\title{
MicroRNA-195 targets VEGFR2 and has a tumor suppressive role in ACHN cells via PI3K/Akt and Raf/MEK/ERK signaling pathways
}

\author{
PENGCHENG SUN ${ }^{1}$, LU WANG $^{1}$, YUNHAN LU ${ }^{1}$, YUWEI LIU ${ }^{1}$, LECHEN LI $^{1}$, LUYAO YIN ${ }^{1}$, \\ CHENG ZHANG $^{3}$, WEIMING ZHAO ${ }^{3}$, BAOZHONG SHEN ${ }^{2}$ and WANHAI XU ${ }^{1,4}$ \\ Departments of ${ }^{1}$ Urology, and ${ }^{2}$ Radiology, The Fourth Hospital of Harbin Medical University; \\ ${ }^{3}$ Department of Urology, The First Hospital of Harbin Medical University, Harbin, Heilongiang 150001; \\ ${ }^{4}$ Heilongjiang Academy of Medical Science, Harbin, Heilongjiang 150001, P.R. China
}

Received February 14, 2016; Accepted June 24, 2016

DOI: 10.3892/ijo.2016.3608

\begin{abstract}
Increasing evidence indicates that dysregulation of miR-195 may contribute to the occurrence and development of multiple types of human malignancies. However, the function and the mechanism of miR-195 in clear cell renal cell carcinoma (ccRCC) are still not fully understood. In the present study, we used qRT-PCR to detect the expression of miR-195 in ccRCC tissues and normal kidney tissues. MTT assay was performed to detect the cell viability of miR-195. Migration and invasion were evaluated by Transwell migration and Matrigel invasion assays, respectively. Additionally, apoptosis levels were evaluated using TUNEL assays, and signaling pathway changes were determined by western blot analysis. We observed that miR-195 was downregulated in clear cell renal cell carcinoma samples compared with normal renal samples. We identified that overexpression of miR-195 inhibited ACHN cell viability, migration, invasion, and it also induced cell apoptosis by targeting VEGFR2 via PI3K/Akt and Raf/MEK/ERK signaling pathways. These findings indicate that miR-195 has a tumor suppressive role in ACHN cells and miR-195 may be a promising candidate target for prevention and treatment of renal cell carcinoma.
\end{abstract}

Correspondence to: Dr Wanhai Xu, Department of Urology, The Fourth Hospital of Harbin Medical University, Harbin, Heilongjiang 150001, P.R. China

E-mail:wanhaixu2015@sina.com

Dr Baozhong Shen, Department of Radiology, The Fourth Hospital of Harbin Medical University, Harbin, Heilongjiang 150001, P.R. China

E-mail: baozhongshen2015@sina.com

Key words: miR-195, clear cell renal cell carcinoma, VEGFR2, $\mathrm{ACHN}$

\section{Introduction}

Renal cell carcinoma (RCC) is the most common renal neoplasm in adults, and clear cell renal cell carcinoma (ccRCC) is the most common pathological type, accounting for approximately $75-80 \%$ of the cases of renal tumors (1). Although most patients can be treated by surgical resection in early stage, there are still many patients who will develop recurrence or the localized tumor will occur distant metastasis. The traditional therapeutic options are still not effective enough on renal cell carcinoma (2). Thus, there is an urgent need for novel diagnosis and treatment of RCC.

MicroRNAs are endogenously expressed single-stranded non-coding RNAs. Their length is approximately 18-25 nucleotides, which can bind to the 3'untranslated region (3'UTR) of target mRNAs, causing degradation of these mRNAs or inhibition of their translation to functional proteins (3). Posttranscriptional regulatory factors, play an important role in the proliferation, differentiation and other biological processes including tumorigenesis (4). MicroRNA-195 is downregulated in a variety of cancers, such as human tongue squamous cell carcinoma (5), gastric (6), breast (7) and ovarian cancer (8). These studies showed that miR-195 acted as an anti-oncogene in these types of cancer. Although Slaby et al (9) have found that the expression level of miR-195 in recurrent tumor is lower, the functional role and mechanism by which miR-195 exerts its activities in clear cell renal cell carcinoma remain to be elucidated. In the present study, we confirmed that microRNA-195 was significantly decreased in renal cell carcinoma tissues compared with non-cancerous renal tissues suggesting that it may participate in the occurrence and development of ccRCC. At the same time, it also suggests that miR-195 may function as a tumor suppressor gene in ccRCC.

\section{Materials and methods}

Human tissue samples. A total of 30 clear cell renal cell carcinoma tissue samples and 30 corresponding non-cancerous renal tissue samples were collected from the patients diagnosed with clear cell renal cell carcinoma $(n=30)$ by the Department 
Table I. The correlation between miR-195 expression and clinicopathological variables of ccRCC.

\begin{tabular}{|c|c|c|c|c|}
\hline Variables & $\begin{array}{l}\text { No. of } \\
\text { patients }\end{array}$ & $\begin{array}{c}\text { Low } \\
\text { expression }\end{array}$ & $\begin{array}{c}\text { High } \\
\text { expression }\end{array}$ & P-value \\
\hline \multicolumn{5}{|c|}{ Age (years) } \\
\hline$<60$ & 10 & 6 & 4 & 0.794 \\
\hline$\geq 60$ & 20 & 11 & 9 & \\
\hline \multicolumn{5}{|l|}{ Gender } \\
\hline Male & 15 & 8 & 7 & 0.712 \\
\hline Female & 15 & 9 & 6 & \\
\hline \multicolumn{5}{|l|}{ Size (cm) } \\
\hline$<3$ & 16 & 9 & 7 & 0.961 \\
\hline$\geq 3$ & 14 & 8 & 6 & \\
\hline \multicolumn{5}{|l|}{ Location } \\
\hline Right & 18 & 10 & 8 & 0.925 \\
\hline Left & 12 & 7 & 5 & \\
\hline \multicolumn{5}{|c|}{ Histological } \\
\hline I, II & 24 & 14 & 10 & 0.713 \\
\hline III, IV & 6 & 3 & 3 & \\
\hline \multicolumn{5}{|l|}{ Metastasis } \\
\hline Yes & 16 & 12 & 4 & 0.028 \\
\hline No & 14 & 5 & 9 & \\
\hline
\end{tabular}

of Urology (the Forth Affiliated Hospital of Harbin Medicine University, Harbin, China). Tissue samples were immediately frozen in liquid nitrogen after surgical removal and classified according to the criteria provided by AJCC (American Joint Committee on Cancer). None of the patients recruited in the present study had undergone preoperative chemotherapy or radiotherapy. Informed written consent was obtained from all patients. The Medical Association Ethics Committee of the Fourth Affiliated Hospital of Harbin Medical University approved all aspects of the present study in accordance with the Helsinki Declaration. Correlation between miR-195 expression and clinicopathological variables of ccRCC are shown in Table I.

RNA isolation and quantitative real-time polymerase chain reaction ( $q R T-P C R)$. Total RNA was extracted from tissues using TRIzol reagent (Invitrogen, Grand Island, NY, USA) according to the manufacturer's protocol. RNA concentrations were measured using the SpectraMax microplate spectrophotometer (Molecular Devices, Sunnyvale, CA, USA). For reverse transcription, $1.0 \mu \mathrm{l}$ of cDNA and SYBR-Green real-time PCR Master Mix (Takara Co., Ltd., Tokyo, Japan) were used according to the manufacturer's protocol. The PCR amplifications were performed in a 96-well plate for 1 cycle of $94^{\circ} \mathrm{C}$ for $30 \mathrm{sec}, 40$ cycles of $95^{\circ} \mathrm{C}$ for $5 \mathrm{sec}$, and $60^{\circ} \mathrm{C}$ for $30 \mathrm{sec}$ on Applied Biosystems 7900HT. The expression level of miR-195 was analyzed by SDS2.4 software (Applied Biosystems) and internally normalized to that of U6 with $2^{-\Delta \Delta C}$ method. The primers of miR-195 and U6 used for qRT-PCR are listed as Table II.
Cell culture and transfection. The human clear cell renal cell carcinoma cell line (ACHN) was purchased from the American Type Culture Collection (ATCC; Manassas, VA, USA) and maintained in Dulbecco's modified Eagle's medium (DMEM; HyClone Laboratories, Logan, UT, USA) supplemented with $10 \%$ fetal bovine serum (FBS; Gibco), $100 \mu \mathrm{g} / \mathrm{ml}$ streptomycin, $100 \mu \mathrm{g} / \mathrm{ml}$ penicillin and incubated at $37^{\circ} \mathrm{C}$ in a humidified incubator at $5 \% \mathrm{CO}_{2}$. ACHN cells were seeded in antibiotic-free medium for $24 \mathrm{~h}$ for transfection. The cells were then transfected with miR-195 mimics $(50 \mathrm{nM})$, miR-195 inhibitor (100 $\mathrm{nM})$ and their respective negative controls (Shanghai GenePharma Co., Ltd., Shanghai, China) using X-treme (Invitrogen, Carlsbad, CA, USA) in serumfree Opti-MEM (Invitrogen) according to the manufacturer's instruction. The negative control (NC) scrambled oligonucleotide does not encode for any known miRNAs. Transfection efficiency was confirmed by SYBR-Green real-time PCR. Cells were collected $48 \mathrm{~h}$ later. All miRNA sequences are listed in Table II.

Cell viability assay. ACHN cells $\left(2 \times 10^{3}\right)$ were seeded in 96-well plates in $100 \mu \mathrm{l}$ culture medium and allowed to attach for $24 \mathrm{~h}$. Then cells were transfected with miR-195 mimics, miR-195 inhibitor, and their corresponding negative controls for $48 \mathrm{~h}$ as we mentioned before. After the treatment, the medium in each well were removed and replaced with PBS solution with $5 \mathrm{mg} / \mathrm{ml}$ 3-'4,5-dimethyl-2-thiazolyl)-2,5-diphenyl-2-H-tetrazolium bromide (MTT) (Sigma-Aldrich, St. Louis, MO, USA) and then the plates were further incubated at $37^{\circ} \mathrm{C}$ for $4 \mathrm{~h}$. The remaining supernatant was then removed and $150 \mu \mathrm{l}$ dimethyl sulfoxide (DMSO; Sigma-Aldrich) was added for $15 \mathrm{~min}$ to dissolve the formed crystal formazan. Finally, the absorbance was measured at $490 \mathrm{~nm}$ using enzyme-labeled analyzer. Three independent experiments were performed.

Cell migration and invasion assays. For migration assay, $5 \times 10^{4}$ cells resuspended in serum-free DMEM after transfection were placed in the upper chamber with $8 \mu \mathrm{m}$ pores (Corning, Corning NY, USA) and incubated at $37^{\circ} \mathrm{C}$ in $5 \% \mathrm{CO}_{2}$ continuously for $24 \mathrm{~h}$. The bottom chamber contained $10 \% \mathrm{FBS}$ as a chemoattractant. After the incubation, the non-migration cells on the upper membrane surface were removed with cotton swab. Cells that had migrated to the bottom of the insert were washed twice with PBS and fixed in $100 \%$ methanol stained with $0.2 \%$ crystal violet. The migrated cells were photographed under a microscope (magnification, x200) and counted in five random fields. Matrigel-precoated Transwell inserts (BD Biosciences, San Jose, CA, USA) were used for the cell invasion assay. Similarly, the lower chamber was filled with $10 \%$ FBS as a chemoattractant. After $24 \mathrm{~h}$ of incubation at $37^{\circ} \mathrm{C}$ in $5 \% \mathrm{CO}_{2}$, the cells that had invaded through the membrane were fixed, stained and counted. Each experiment was performed in triplicate.

Cell cycle analysis. The influence of the change of cell cycle was analyzed by flow cytometry. The transfected ACHN cells ( $1 \times 10^{6}$ cells) were washed with PBS and fixed in $70 \%$ ethanol overnight at $4^{\circ} \mathrm{C}$. The cells were then labeled with propidium iodide $(50 \mu \mathrm{g} / \mathrm{ml})$ and RNase $(100 \mu \mathrm{g} / \mathrm{ml})$ (Sigma-Aldrich) for $30 \mathrm{~min}$ and were analyzed using a fluorescence-activated 
Table II. Sequences of primers for qRT-PCR and miR-195 related sequence.

\begin{tabular}{ll} 
Name & \multicolumn{1}{c}{ Sequence (5'-3') } \\
\hline $\begin{array}{l}\text { Primers used for mRNA detection } \\
\text { miR-195 (Forward) }\end{array}$ & GGGGTAGCAGCACAGAAAT \\
miR-195 (Reverse) & TCCAGTGCGTGTCGTGGA \\
miR-195 (RT) & (GTCGTATCCAGTGCGTGTCGTGGAGTCGGCAATTGCACTGGATACGACGCCAAT) \\
U6 (Forward) & GCTTCGGCAGCACATATACTAAAAT \\
U6 (Reverse) & CGCTTCACGAATTTGCGTGTCAT \\
U6 (RT) & (GTCGTATCCAGTGCGTGTCGTGGAGTCGGCAATTGCACTGGATACGACTACATAC)
\end{tabular}

Gene names

miR-195 mimics

UAGCAGCACAGAAAUAUUGGC

Mimics NC

UUCUCCGAACGUGUCACGUTT

miR-195 inhibitor

GCCAAUAUUUCUGUGCUGCUA

Inhibitor NC

CAAUAUUUCUGUGCUGCUAUU

cell sorter scanning (Becton-Dickinson, San Jose, CA, USA). The percentages of $G_{0} / G_{1}, S$ and $G_{2} / M$ cells were counted and compared. Each experiment was performed in triplicate.

TUNEL assay and DAPI staining. Cell apoptosis was measured by TUNEL/DAPI double staining assay as the manual recommended. The ACHN cells were seeded in coverslips in 6-well plates with the same cell number per well $\left(1 \times 10^{5}\right)$. Cells harvested $48 \mathrm{~h}$ after transfection were washed with PBS/1\% BSA and fixed in paraformaldehyde solution (4\% in PBS) for $20 \mathrm{~min}$ at room temperature. After washing with PBS three times, the cells were permeabilized in a solution containing $0.1 \%$ Triton $\mathrm{X}-100$ in $0.1 \%$ sodium citrate for $2 \mathrm{~min}$ on ice, followed by incubation in freshly prepared TUNEL reaction mixture terminal deoxynucleotidyl transferase (TdT) and TUNEL dilution buffer at the ratio of 1:10 for $60 \mathrm{~min}$ at $37^{\circ} \mathrm{C}$ in the dark. Then anti-digoxigenin peroxidase conjugate was added, and incubation continued in a humid box for $30 \mathrm{~min}$ at room temperature. After washing with PBS three times, DAPI (Roche Molecular Biochemicals) was added for $10 \mathrm{~min}$ at room temperature to stained nuclei. The coverslips were then washed with PBS three times and manipulated with anti-fading solution. Finally, the cells were observed on slides by a confocal microscope (Olympus FluoView ${ }^{\mathrm{TM}}$ FV1000).

Western blot analysis. Total protein samples were extracted from transfected ACHN cells using lysis buffer containing protease inhibitor. The protein concentrations were measured using the Bio-Rad protein assay system (Bio-Rad Laboratories, Hercules, CA, USA). After boiling the samples for $5 \mathrm{~min}$, the protein samples were run on SDS-PAGE (8-15\% polyacrylamide gels). The lysates were resolved by electrophoresis $(70 \mathrm{~V}$ for $25 \mathrm{~min}$ and $120 \mathrm{~V}$ for $1.5 \mathrm{~h}$ ) and transferred onto $\mathrm{NC}$ membranes (nitrocellulose membrane; Bio-Rad Laboratories). After blocking in 5\% non-fat milk in Tris-buffered saline with Tween (TBST) for $2 \mathrm{~h}$, the NC membranes were treated overnight at $4^{\circ} \mathrm{C}$ with the following primary antibodies: Bax (1:200 dilution; Cell Signaling Technology, Danvers, MA, USA), caspase-3 (1:200 dilution; Cell Signaling Technology),
Bcl-2 (1:200 dilution; Cell Signaling Technology), VEGFR2 (1:200 dilution; Abcam, Cambridge, MA, USA), total-Akt (1:200 dilution; Santa Cruz Biotechnology, Santa Cruz, CA USA), p-Akt (1:500 dilution; Cell Signaling Technology), Raf (1:500 dilution; Cell Signaling Technology), MEK (1:500 dilution; Cell Signaling Technology) ERK (1:500 dilution; Cell Signaling Technology), p-ERK1/2 (p44/p42) (1:500 dilution; Cell Signaling Technology). The next day, the NC membranes were washed in PBS three times and incubated with secondary antibody: Alexa Fluor ${ }^{\circledR} 800$ goat anti-mouse or anti-rabbit IgG (Invitrogen) diluted at 1:4,000 at room temperature for $1.5 \mathrm{~h}$. Western blot bands were quantified using Odyssey v1.2 software by measuring the band intensity (Area x OD; Optical Density) for each group and normalized to GAPDH (glyceraldehyde-3-phosphate). All the presented results are representative of at least three independent experiments.

Luciferase assay. To generate reporter vectors bearing miRNA-binding sites, the 3'-untranslated region (3'-UTR) of VEGFR2 and its mutation type were synthesized. The construct was inserted into multiple cloning sites downstream of the luciferase gene ( $\mathrm{SacI}$ and HindIII sites) in the pMIRREPORT luciferase miRNA expression reporter vector (Ambion, Austin, TX, USA). For the luciferase assay, $0.1 \mu \mathrm{g}$ of luciferase reporters containing 3'-UTR were cotransfected with miR-195 or miR-195 inhibitor into HEK-293 cells using Lipofectamine 2000 (Invitrogen). As an internal control, $10 \mathrm{ng}$ of Renilla luciferase reporters were also included. Forty-eight hours after transfection, the cells were collected and DualLuciferase activities were measured by a luminometer.

Data analysis. Data were analyzed using the GraphPad Prism 5.0 and the SPSS 14.0. The data were presented as mean \pm SEM. Two-tailed unpaired Student's t-tests and one-way ANOVA were used for the statistical evaluation of the data. The Chi-squared test was used to investigate the significance of miR-195 expression as correlated with clinicopathological features in renal cell carcinoma. $\mathrm{P}<0.05$ was considered as indicating statistically significant differences. 


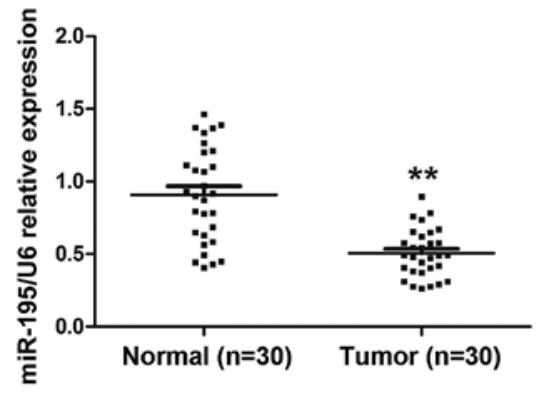

Figure 1. The expression of miR-195 in clear cell renal cell carcinoma tissues compared to normal kidney tissues. qRT-PCR was performed to respectively detect the expression of miR-195 in 30 pairs of ccRCC and corresponding non-cancerous kidney tissues. The mean expression level of miR-195 was significantly lower in clear cell renal cell carcinoma tissues compared with normal kidney tissues. U6 was used as an internal control. Data represent mean \pm SEM from three independent experiments $\left({ }^{* *} \mathrm{P}<0.01\right)$.

\section{Results}

Expression of miR-195 is decreased in ccRCC tissues and associated with lymph node metastasis. To detect the expression and significance of miR-195 in ccRCC tumorigenesis, we compared miR-195 expression profiles between ccRCC tissues and paired adjacent non-cancerous renal tissues from 30 individual patients using quantitative RT-PCR. The results showed that miR-195 expression was significantly decreased in ccRCC tissues compared with adjacent non-cancerous renal tissues (Fig. 1; P<0.01). Next we analyzed the association between miR-195 expression and clinicopathological features in the 30 ccRCC patients. The relationship between miR-195 levels and patients' clinical features suggests that expression of miR-195 was correlated with metastasis, while no obvious correlation was observed in the patient gender, age, tumor size or location (Table I). These results suggest that the change of miR-195 expression level may affect the occurrence and development of ccRCC. miR-195 may act as a tumor suppressor gene in ccRCC.

miR-195 inhibits ACHN cell viability in vitro. To explore the effect of miR-195 on the biological behavior of ccRCC, we transfected ACHN cells with miR-195 mimics, miR-195 inhibitor and their corresponding negative controls as mentioned above. The expression of miR-195 in ACHN cells was detected in order to guarantee the efficiency of transfection. Each group of transfected cells was compared with the NC. In the miR-195 mimics group, miR-195 expression was significantly higher than the mimic NC group. There was also a notable decrease in miR-195 expression in the miR-195 inhibitor group as compared to the mimics group (Fig. $2 \mathrm{~A} ; \mathrm{P}<0.01$ ). The transfected cells were then used to do the viability assay. The experimental results showed that the viability of ACHN cells was suppressed by overexpressing miR-195 compared with that of control (Fig. 2B; $\mathrm{P}<0.01$ ).

miR-195 attenuates migration and invasion potential of ACHN cells in vitro. Invasiveness and migratory capacity of the tumor cells are essential for tumor progression. To test whether miR-195 worked on migratory and invasive capabilities of ACHN cells, Transwell and Matrigel invasion assays were performed in vitro. The results showed that the
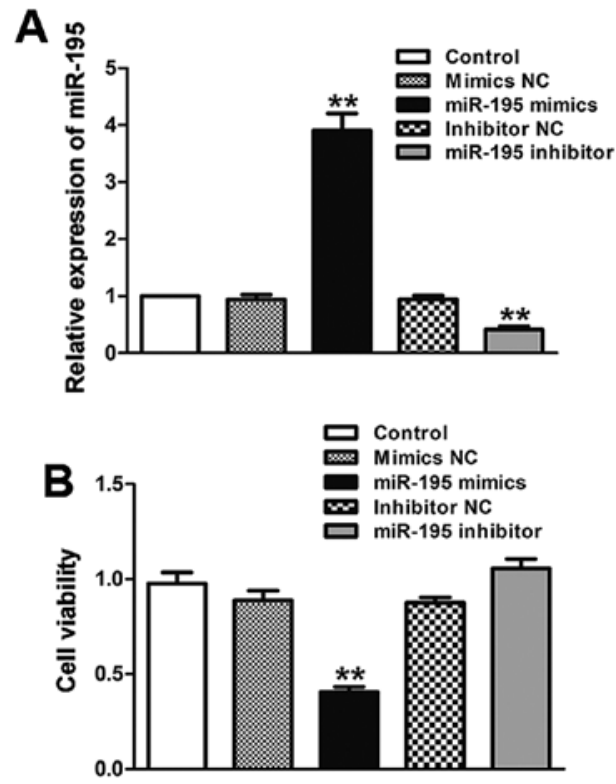

Figure 2. The expression of miR-195 in transfected ACHN cells. (A) ACHN cells were transiently transfected with miR-195 mimics (50 nM), miR-195 inhibitor (100 nM), and the negative controls, respectively. This effect was examined by SYBR-Green qRT-PCR and normalized to U6 expression. Data represent mean \pm SEM from three independent experiments $\left({ }^{* *} \mathrm{P}<0.01\right)$. (B) miR-195 inhibits the viability of ACHN cells. Cell viability was determined by MTT assay after transfection. Data represent mean \pm SEM from three independent experiments $\left({ }^{* *} \mathrm{P}<0.01\right)$.

migratory capability of ACHN cells transfected with miR-195 was reduced by $45.3 \%$ in x200 magnification (Fig. 3A and $\mathrm{C} ; \mathrm{P}<0.05)$. In order to further verify the effect of miR-195 on ACHN cell metastasis, Matrigel invasion assays was performed. Similarly, the Matrigel invasion assay showed that the invasiveness of ACHN cells was reduced by $41.6 \%$ compared to control group (Fig. 3B and D; $\mathrm{P}<0.01$ ). In conclusion, these results suggest that overexpression of miR-195 can suppress ACHN cells migration and invasion.

miR-195 induces cell cycle arrest in ACHN cells. By exploring the effects of miR-195 on cell cycle distribution, we can learn more about the intrinsic mechanism of miR-195 on cell proliferation. As compared with control in Fig. 4, the percentage of cells in $S$ and $G_{2}$ phase was significantly increased upon treatment with miR-195 mimics.

miR-195 induces apoptosis in ACHN cells. To investigate whether miR-195 can induce ACHN cells to apoptosis, TUNEL assays were used to confirm apoptosis changes. DAPI positive cells showed that total number of each group were almost the same (Fig. 5A, upper panel). In the TUNEL staining, the merged pictures showed the double labeled cells which were the ACHN cells occurring apoptosis (Fig. 5A, lower panel). From the statistical graph, we found that the apoptotic rate of ACHN cells increased when the cells were treated by miR-195 mimics $(\mathrm{P}<0.01 ;$ Fig. 5B). Taken together, these data indicated that miR-195 can induce apoptosis in ACHN cells compared with normal groups.

miR-195 overexpression inhibits Bcl-2 expression, and boosts Bax, caspase-3 proteins expression in the process of 


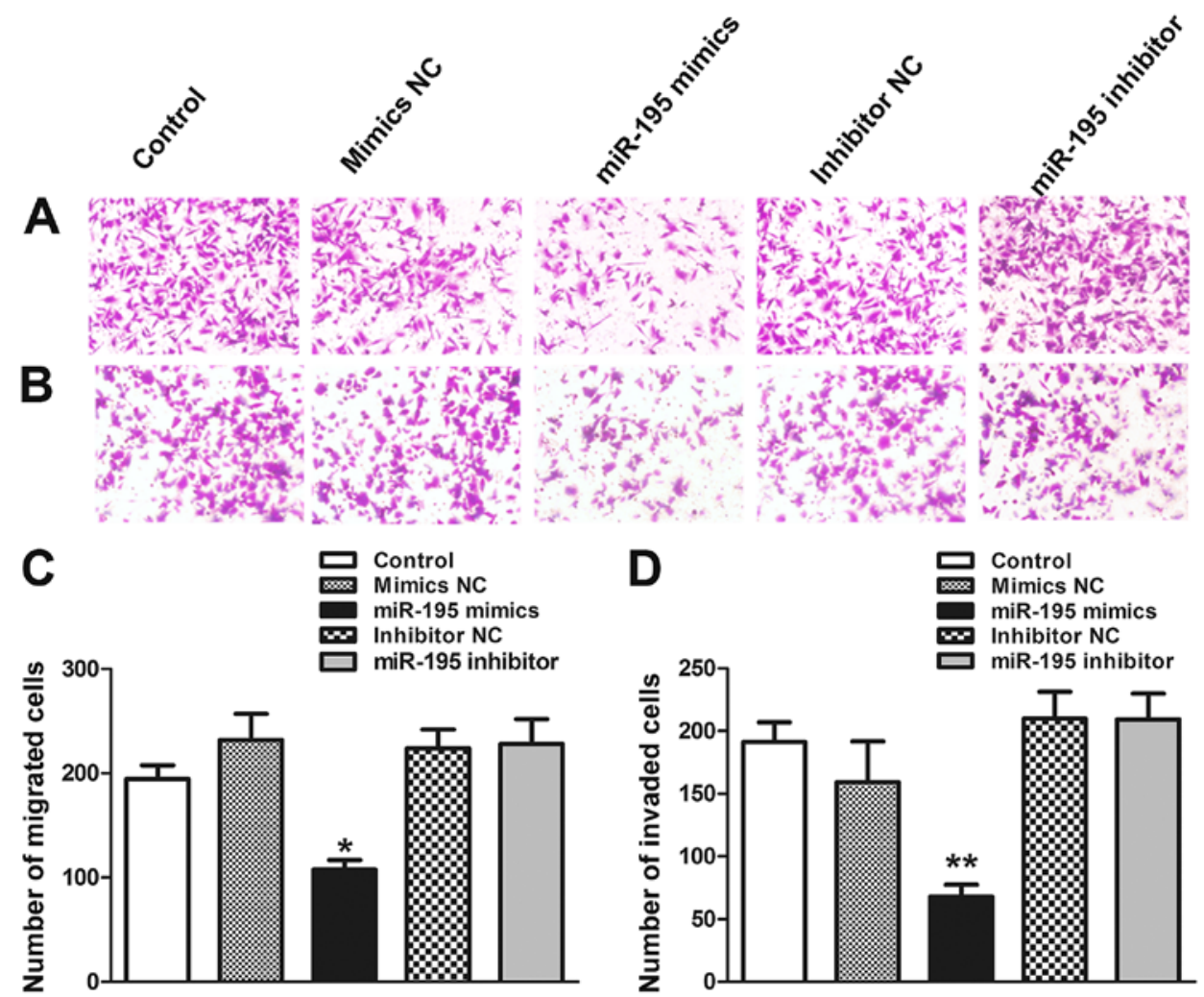

Figure 3. miR-195 inhibits the migration and invasion of ACHN cells. (A) The wound healing assays (magnification, x200) of ACHN cells. (B) Images represented the cells travelled through the membrane by Transwell assay (magnification, x200). The histogram showed the number of migrated cells. Data represent mean \pm SEM from three independent experiments $\left({ }^{* * *} \mathrm{P}<0.01\right)$. (C) Images represent the cells passing through the Matrigel by Matrigel invasion assay (magnification, $\mathrm{x} 200$ ). (D) The histogram shows the number of invaded cells. Data represent mean \pm SEM from three independent experiments $\left({ }^{* *} \mathrm{P}<0.01\right)$.
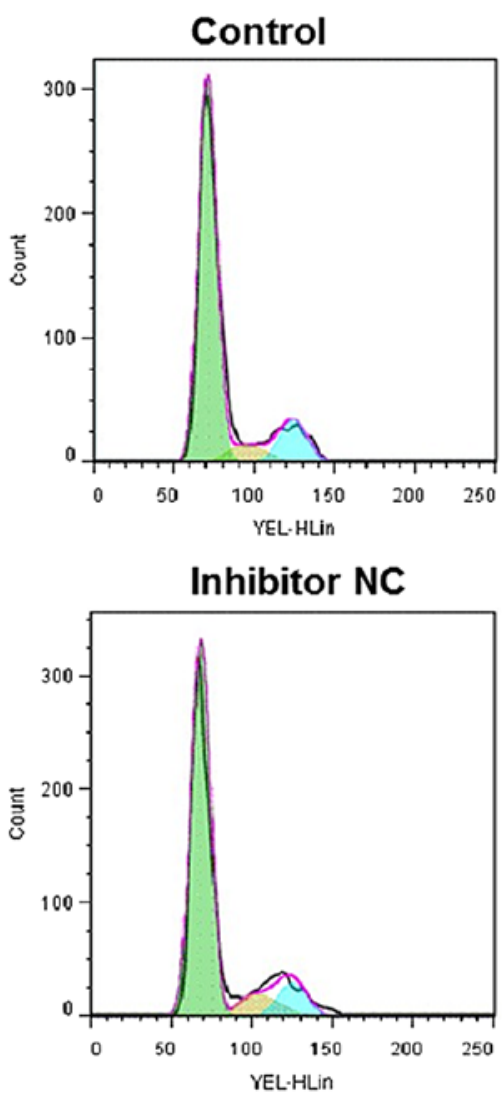

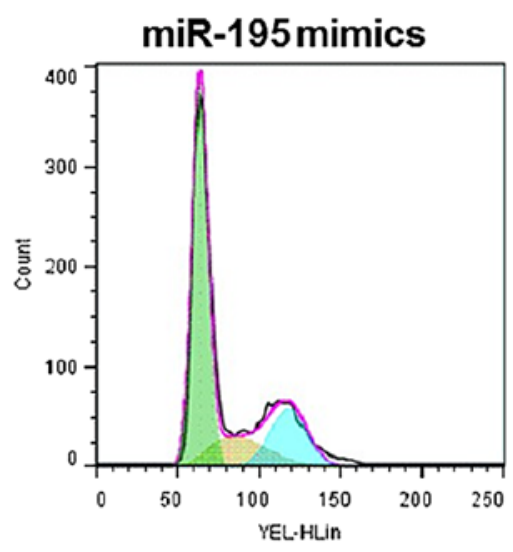

miR-195 inhibitor
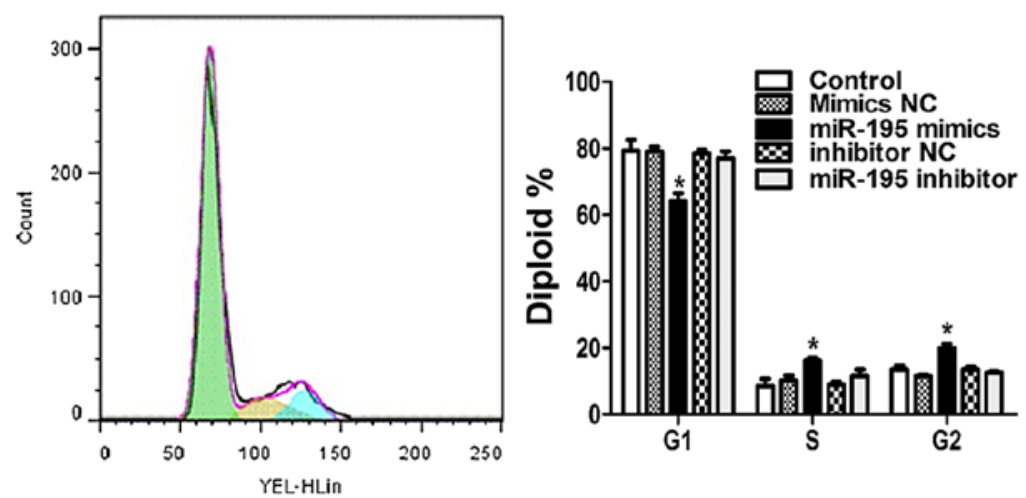

Figure 4. Effect of miR-195 on ACHN cell cycle. Cells were harvested for cell cycle analysis by flow cytometry $48 \mathrm{~h}$ after the transfection. Overexpression of miR-195 significantly caused $\mathrm{S}$ and $\mathrm{G}_{2}$ phases arrest in ACHN cells compared to control group. 


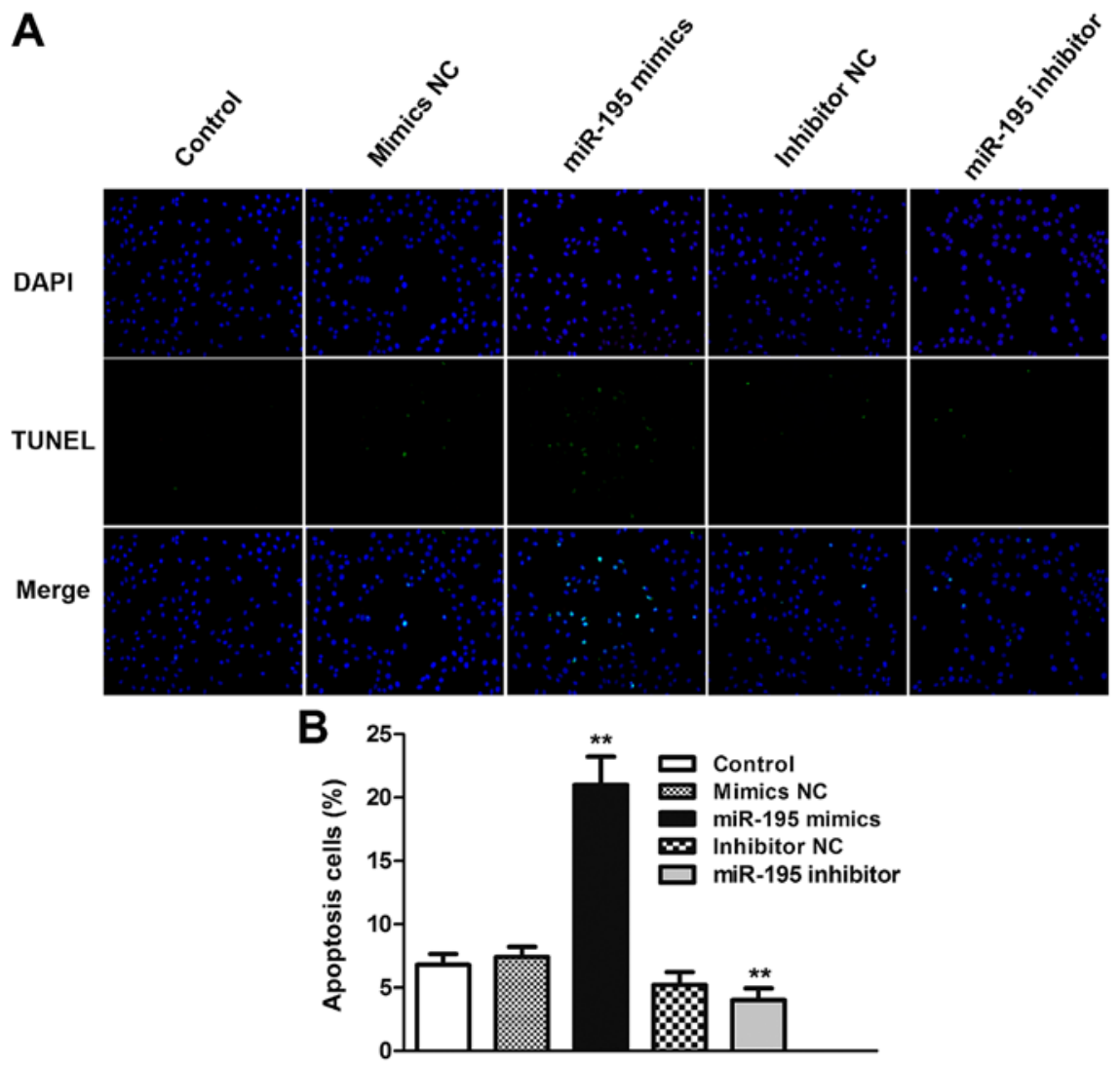

Figure 5. Overexpression of miR-195 induces ACHN cells apoptosis in vitro. (A) Representative DAPI and TUNEL stained photomicrographs from the five groups of ACHN cells with different treatments. Blue is the cell nucleus stained by DAPI; green is TUNEL staining representing apoptotic cells. Original magnification, $x 200$. Data represent mean \pm SEM from three independent experiments ( $\left.{ }^{* *} \mathrm{P}<0.01\right)$. (B) Quantitative analysis of the apoptosis rate from five groups of ACHN cells with different treatments.
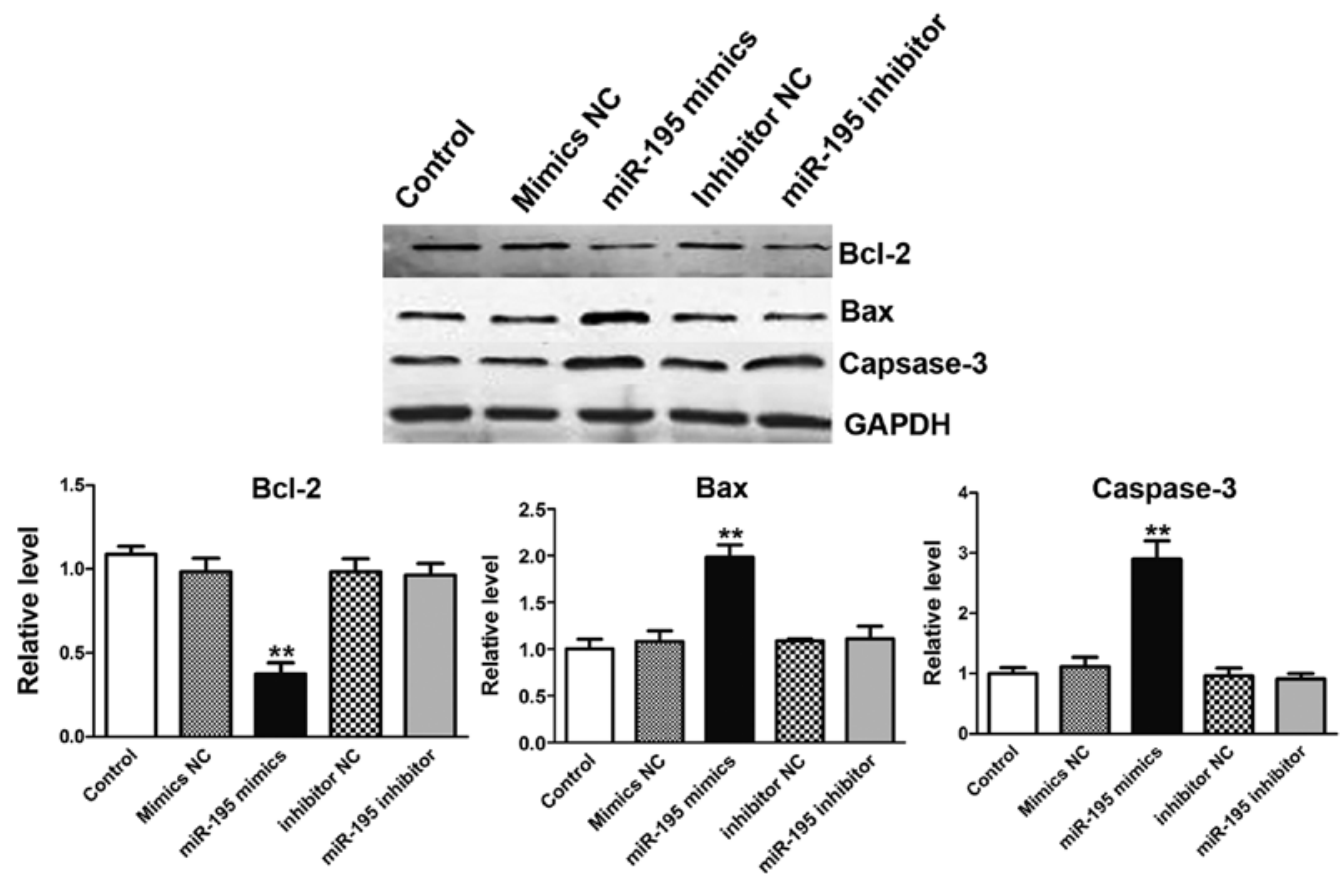

Figure 6. Expression level of Bcl-2, Bax and caspase-3 proteins in transfected cells. Cell lysates were prepared and used for western blot analysis of Bcl-2, Bax and cleaved caspase-3 in different groups. Data are expressed as mean \pm SEM from three independent experiments $\left({ }^{* *} \mathrm{P}<0.01\right)$.

apoptosis. Apoptosis is a complex process which involves a series of proteins. Bcl-2 is a member of the human inhibitors of apoptosis protein family (10). Bcl-2 expression in cancer has been implicated not only in inhibition of apoptosis, 

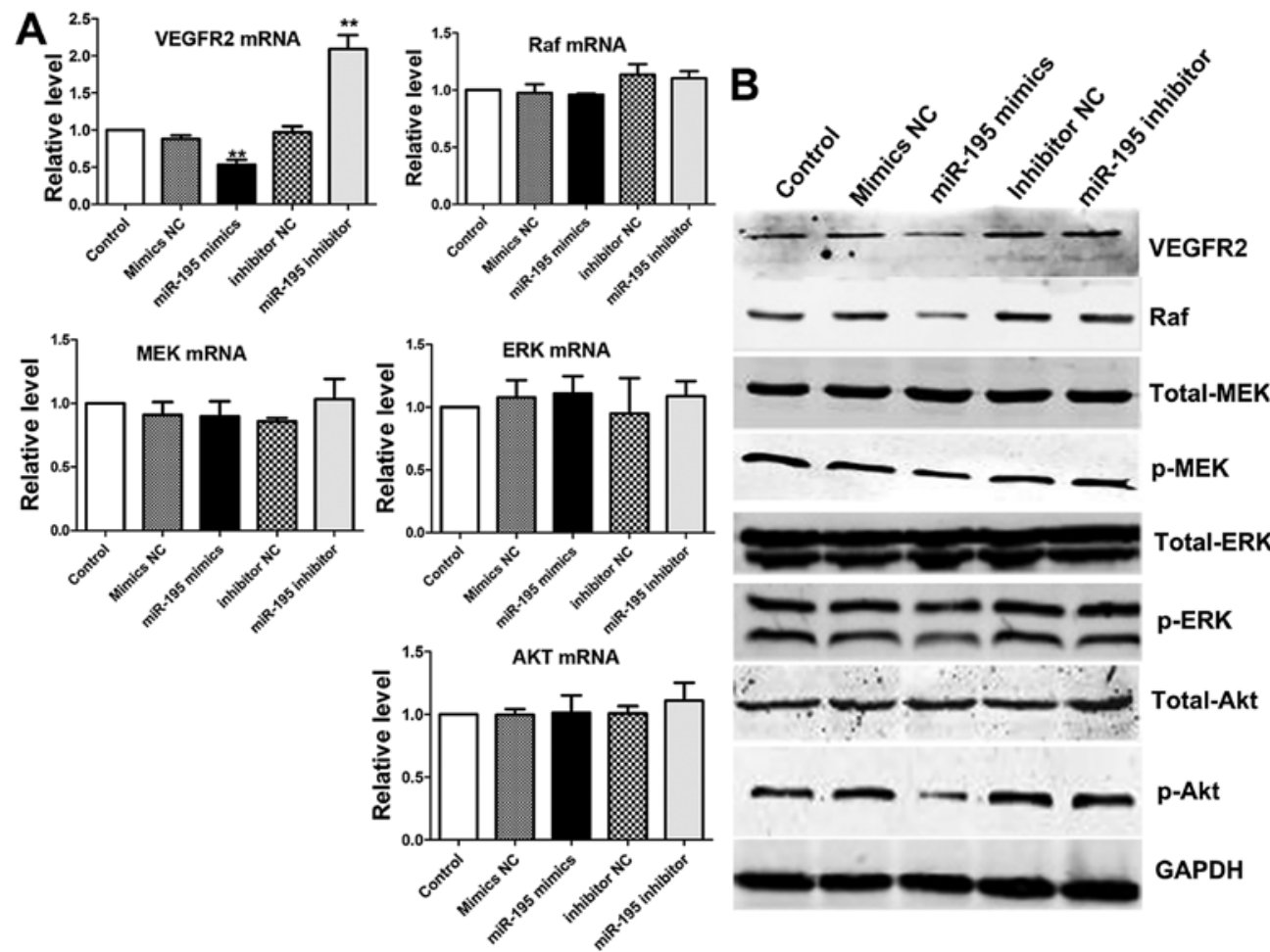
p-ERK
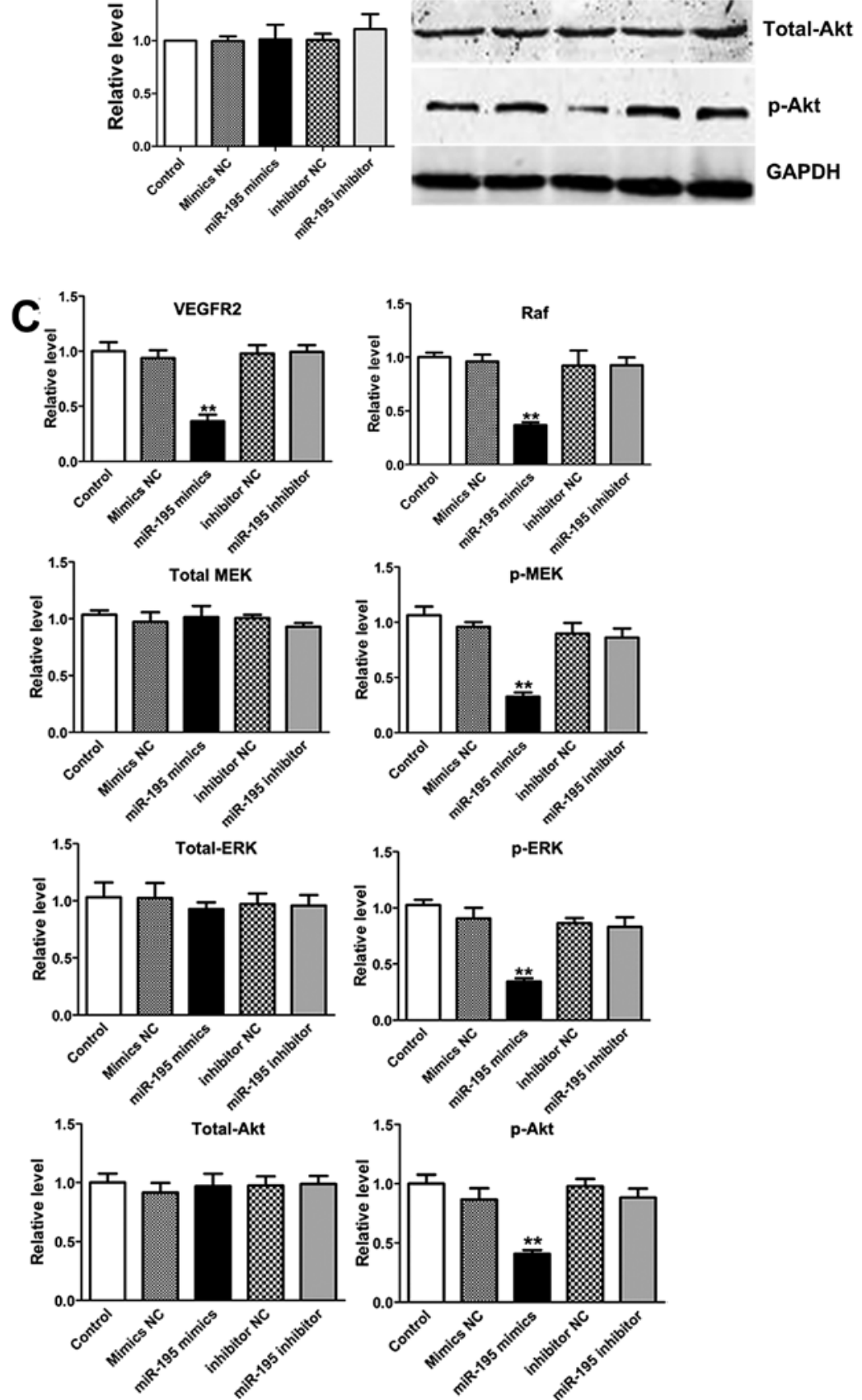

Figure 7. Raf/MEK/ERK and PI3K/Akt signaling pathways are suppressed by miR-195. (A) The regulation of miR-195 on mRNA of Raf, MEK, ERK and Akt. (B) Total-Raf, MEK, ERK and Akt; phospho-MEK, ERK and Akt were measured by western blot analysis. Data are expressed as mean \pm SEM from three independent experiments $\left({ }^{* *} \mathrm{P}<0.01\right.$ compared with control group). 


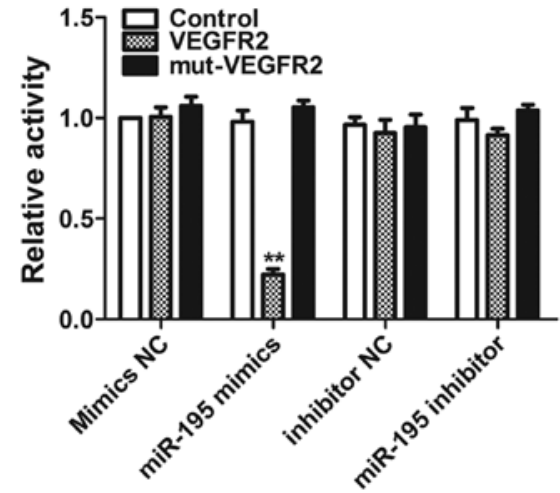

Figure 8. VEGFR2 is a direct target of miR-195. The luciferase activities were analyzed in HEK 293 cells $48 \mathrm{~h}$ after transfection. The data are presented as the means \pm SEM of three separate experiments; ${ }^{* *} \mathrm{P}<0.01$.

but also related to promotion of proliferation (11). On the country, Bax and caspase-3 are symbols for apoptosis (12-14). To further confirm the apoptosis effect induced by miR-195, western blot analysis was used to detect the apoptosis-related proteins as mentioned before. In treatment of ACHN cells with miR-195 mimics, the expression of Bcl-2 expression was depressed (Fig. 6A). Interestingly, Bax in cell extracts was increased (Fig. 6B). Furthermore, cells transfected with miR-195 resulted in the significant increase in expression level of relative caspase- 3 suggesting the involvement of cell apoptosis prompted by miR-195 (Fig. 6C) (15). When ACHN cells were transfected with miR-195 inhibitor, no obvious phenomenon was observed.

miR-195 can regulate PI3K/Akt and Raf/MEK/ERK signaling pathway via targeting VEGFR2. It has been reported that VEGFR2 is not only a vital signal receptor, but also involved in the regulation of cellular processes, including survival, growth, migration, invasion, apoptosis and angiogenesis (16-21). Furthermore, its downstream signaling pathways phosphatidylinositol 3-kinase (PI3K/Akt) occupied a central position in the pathogenesis of renal cell carcinoma (22). In addition, the downstream signaling pathway: Raf/MEK/ERK pathway is involved in the proliferation and inhibition of apoptosis (23-25). Thus, we investigated whether VEGFR2 could be regulated by miR-195, which had an inhibitory effect on ACHN cells through PI3K/Akt and Raf/MEK/ERK signaling pathways. We used qRT-PCR and western blot analysis to detect the expression levels of VEGFR-2 and its downstream signal molecules: Akt, MEK and ERK in different groups, tyrosine phosphorylation of these proteins is essential for cancer cell proliferation $(26,27)$. The results indicated miR-195 suppressed the VEGFR2 mRNA, but had no effect on mRNA of MEK, ERK or Akt. Then, western blot analysis was performed to analyze the effect on proteins induced by miR-195 (Fig. 7A). The expression level of VEGFR2 was significantly reduced and its active downstream factors: Raf, p-MEK and p-ERK $1 / 2$ were dramatically decreased following downregulation of VEGFR2 in ACHN cells. However, the expression of total MEK and total ERK1/2 remained only slightly changed after transfection in ACHN cells compared with control groups. We noted that the level of total-Akt was almost the same in overexpression miR-195 ACHN cells compared with control groups. As expected, the level of p-Akt was decreased in overexpression miR-195 ACHN cells compared with control groups (Fig. 7B and C). Based on these results, we confirmed that overexpression of miR-195 in ACHN cells suppressed the phosphorylation of MEK, ERK and Akt, which are the downstream targets of VEGFR2. These processes could come through PI3K/Akt and RAF/MEK/ERK two signal pathways.

VEGFR2 is a direct target of miR-195. To further validate whether VEGFR2 is a direct target of miR-195, luciferase reporter constructs containing a segment of the 3'-UTR of VEGFR2 (VEGFR2) or a mutated 3'-UTR of VEGFR2, which contained a mutated seed sequence (mut-VEGFR2), were generated (Fig. 8). The constructs were co-transfected with miR-195 into HEK293 cells. Co-transfection of miR-195 strongly inhibited the luciferase activity of the reporter construct containing the $3^{\prime}$-UTR.

\section{Discussion}

The formation of renal cell carcinoma is a complex process which involves changes of various genes $(28,29)$. A class of endogenous, single stranded, small non-coding RNAs, are known as miRNAs which can regulate multiple function gene expression at the post-transcriptional level and play important roles in biological processes such as cell differentiation, proliferation and apoptosis $(3,4)$. Emerging evidence show that aberrant expression of microRNAs may contribute to kidney tumorigenesis $(30,31)$. Recently, it has been shown that some microRNAs inhibit cancer via suppressing certain cytokines. For example, hepatocellular carcinoma was inhibited by miR-195 through VEGF inhibition and colorectal cancer was inhibited by miR-497 via regulating IGF1 $(32,33)$. Slaby et al $(9)$ showed that miR-195 was decreased in tumors from patients who developed relapse and in primary metastasis. In the present study, we confirmed that by qRT-PCR and considered miR-195 may play an important role in ccRCC progression. As expected, the viability of ACHN cells was suppressed by miR-195 mimics, the migratory and invasive activities were inhibited compared to that of the control. In addition, bioinformatic analysis shows that VEGFR2 is a potential target of miR-195. We first identified that miR-195 targets VEGFR2 in ACHN cells and then investigated the downstream signaling moleculars further in this study. Renal cell carcinoma (RCC), is the second most common form of urologic tumor associated with an alteration of multiple signaling pathways (34). In addition, the PI3K/Akt pathway plays a critical role in kidney cancer pathogenesis. The p-Akt then activates a series of cancer-related functions such as cell growth, proliferation, survival and motility, which drive tumor progression $(35,36)$. We found that overexpression of miR-195 significantly downregulated p-Akt protein expression in ACHN cells. Likewise, the expression of $\mathrm{p}$-Raf and its downstream proteins $\mathrm{p}-\mathrm{MEK}$, p-ERK were decreased. The expression level of total Akt, total MEK, and total ERK had little change before and after transfection. Furthermore, we found that increased Bax and caspase-3 proteins, and attenuated expression of Bcl-2 protein level in transfected miR-195 mimics ACHN cells. In summary, overexpression miR-195 could inhibit activation of PI3K/Akt and Raf/MEK/ERK signaling pathways, which play critical 
roles in cell proliferation, migration and apoptosis. A schema of the role of miR-195 in ACHN cells is shown in Fig. 7. Our findings provided a theoretical basis for further research on the mechanism of miR-195 in renal clear cell carcinoma, and provide a direction for gene therapy for renal cell carcinoma.

To the best of our knowledge, VEGFR2 is an important receptor of VEGF (vascular endothelium derived factor) reported to be powerful in promoting angiogenesis function (37). Angiogenesis plays an important role in the process of renal cell carcinoma (38). Hence we intend to focus on the anti-angiogenesis role of miR-195 in renal cell carcinoma in future research.

In conclusion, miR-195 suppresses ACHN proliferation and potentiates apoptosis by inhibiting both the Raf/MEK/ERK and the PI3K/Akt pathways via targeting VEGFR2. This may provide promising targets for ccRCC which remains an incurable disease. Overexpression of miR-195 could be considered as a potential therapeutic strategy for ccRCC therapy. More research will be required before applying it in the clinic.

\section{Acknowledgements}

The present study was supported by the National Natural Science Foundation of China (30900354).

\section{References}

1. Rasmussen F: Metastatic renal cell cancer. Cancer Imaging 13: 374-380, 2013.

2. Ljungberg B, Cowan NC, Hanbury DC, Hora M, Kuczyk MA, Merseburger AS, Patard JJ, Mulders PF and Sinescu IC; European Association of Urology Guideline Group: EAU guidelines on renal cell carcinoma: The 2010 update. Eur Urol 58: 398-406, 2010.

3. Lujambio A and Lowe SW: The microcosmos of cancer. Nature 482: 347-355, 2012.

4. Saxena S, Jónsson ZO and Dutta A: Small RNAs with imperfect match to endogenous mRNA repress translation. Implications for off-target activity of small inhibitory RNA in mammalian cells. J Biol Chem 278: 44312-44319, 2003.

5. Jia LF, Wei SB, Gong K, Gan YH and Yu GY: Prognostic implications of micoRNA miR-195 expression in human tongue squamous cell carcinoma. PLoS One 8: e56634, 2013.

6. Deng H, Guo Y, Song H, Xiao B, Sun W, Liu Z, Yu X, Xia T, Cui L and Guo J: MicroRNA-195 and microRNA-378 mediate tumor growth suppression by epigenetical regulation in gastric cancer. Gene 518: 351-359, 2013.

7. Heneghan HM, Miller N, Kelly R, Newell J and Kerin MJ: Systemic miRNA-195 differentiates breast cancer from other malignancies and is a potential biomarker for detecting noninvasive and early stage disease. Oncologist 15: 673-682, 2010.

8. Kim YW, Kim EY, Jeon D, Liu JL, Kim HS, Choi JW and Ahn WS: Differential microRNA expression signatures and cell type-specific association with Taxol resistance in ovarian cancer cells. Drug Des Devel Ther 8: 293-314, 2014.

9. Slaby O, Redova M, Poprach A, Nekvindova J, Iliev R, Radova L, Lakomy R, Svoboda M and Vyzula R: Identification of MicroRNAs associated with early relapse after nephrectomy in renal cell carcinoma patients. Genes Chromosomes Cancer 51 : 707-716, 2012

10. Hardwick JM and Soane L: Multiple functions of BCL-2 family proteins. Cold Spring Harb Perspect Biol 5: a008722, 2013.

11. Davids MS and Letai A: Targeting the B-cell lymphoma/ leukemia 2 family in cancer. J Clin Oncol 30: 3127-3135, 2012.

12. Yip KW and Reed JC: Bcl-2 family proteins and cancer. Oncogene 27: 6398-6406, 2008

13. Antonsson B: Bax and other pro-apoptotic Bcl-2 family 'killerproteins' and their victim the mitochondrion. Cell Tissue Res 306: 347-361, 2001.

14. Li CL, Chang L, Guo L, Zhao D, Liu HB, Wang QS, Zhang P, Du WZ, Liu X, Zhang HT, et al: $\beta$-elemene induces caspasedependent apoptosis in human glioma cells in vitro through the upregulation of Bax and Fas/ FasL and downregulation of Bcl-2. Asian Pac J Cancer Prev 15: 10407-10412, 2014.
15. Zhang W, Ha M, Gong Y, Xu Y, Dong N and Yuan Y: Allicin induces apoptosis in gastric cancer cells through activation of both extrinsic and intrinsic pathways. Oncol Rep 24: 1585-1592, 2010.

16. Lang SA, Schachtschneider P, Moser C, Mori A, Hackl C, Gaumann A, Batt D, Schlitt HJ, Geissler EK and Stoeltzing O: Dual targeting of Raf and VEGF receptor 2 reduces growth and metastasis of pancreatic cancer through direct effects on tumor cells, endothelial cells, and pericytes. Mol Cancer Ther 7: 3509-3518, 2008.

17. Chen CH, Lai JM, Chou TY, Chen CY, Su LJ, Lee YC, Cheng TS, Hong YR, Chou CK, Whang-Peng J, et al: VEGFA upregulates FLJ10540 and modulates migration and invasion of lung cancer via PI3K/AKT pathway. PLoS One 4: e5052, 2009.

18. Pal HC1, Sharma S, Strickland LR, Agarwal J, Athar M, Elmets CA and Afaq F: Delphinidin reduces cell proliferation and induces apoptosis of non-small-cell lung cancer cells by targeting EGFR/VEGFR2 signaling pathways. PLoS One 8: e77270, 2013

19. Sakurai Y, Ohgimoto K, Kataoka Y, Yoshida N and Shibuya M: Essential role of Flk-1 (VEGF receptor 2) tyrosine residue 1173 in vasculogenesis in mice. Proc Natl Acad Sci USA 102: 1076-1081, 2005.

20. Fontanella C, Ongaro E, Bolzonello S, Guardascione M, Fasola G and Aprile G: Clinical advances in the development of novel VEGFR2 inhibitors. Ann Transl Med 2: 123, 2014.

21. Claesson-Welsh L and Welsh M: VEGFA and tumour angiogenesis. J Intern Med 273: 114-127, 2013.

22. Conti A, Santoni M, Amantini C, Burattini L, Berardi R, Santoni G, Cascinu S and Muzzonigro G: Progress of molecular targeted therapies for advanced renal cell carcinoma. BioMed Res Int 2013: 419176, 2013

23. Troppmair J and Rapp UR: Raf and the road to cell survival: A tale of bad spells, ring bearers and detours. Biochem Pharmacol 66: 1341-1345, 2003.

24. Stadler WM: Targeted agents for the treatment of advanced renal cell carcinoma. Cancer 104: 2323-2333, 2005.

25. Sridhar SS, Hedley D and Siu LL: Raf kinase as a target for anticancer therapeutics. Mol Cancer Ther 4: 677-685, 2005.

26. Chan CH, Jo U, Kohrman A, Rezaeian AH, Chou PC, Logothetis C and Lin HK: Posttranslational regulation of Akt in human cancer. Cell Biosci 4: 59, 2014.

27. Shaul YD and Seger R: The MEK/ERK cascade: From signaling specificity to diverse functions. Biochim Biophys Acta 1773: 1213-1226, 2007.

28. Walker C: Molecular genetics of renal carcinogenesis. Toxicol Pathol 26: 113-120, 1998.

29. Bussolati B, Satolli MA and Camussi G: The role of angiogenesis in renal carcinoma. G Ital Nefrol 25: 297-305, 2008 (In Italian).

30. Redova M, Svoboda M and Slaby O: MicroRNAs and their target gene networks in renal cell carcinoma. Biochem Biophys Res Commun 405: 153-156, 2011.

31. Ma L and Qu L: The function of microRNAs in renal development and pathophysiology. J Genet Genomics 40: 143-152, 2013.

32. Wang R, Zhao N, Li S, Fang JH, Chen MX, Yang J, Jia WH, Yuan Y and Zhuang SM: MicroRNA-195 suppresses angiogenesis and metastasis of hepatocellular carcinoma by inhibiting the expression of VEGF, VAV2, and CDC42. Hepatology 58: 642-653, 2013

33. Guo ST, Jiang CC, Wang GP, Li YP, Wang CY, Guo XY, Yang RH, Feng Y, Wang FH, Tseng HY, et al: MicroRNA-497 targets insulin-like growth factor 1 receptor and has a tumour suppressive role in human colorectal cancer. Oncogene 32: 1910-1920, 2013

34. Kim WY and Kaelin WG Jr: Molecular pathways in renal cell carcinoma - rationale for targeted treatment. Semin Oncol 33: $588-595,2006$

35. Vivanco I and Sawyers CL: The phosphatidylinositol 3-kinase AKT pathway in human cancer. Nat Rev Cancer 2: 489-501, 2002.

36. Li F, Ambrosini G, Chu EY, Plescia J, Tognin S, Marchisio PC and Altieri DC: Control of apoptosis and mitotic spindle checkpoint by survivin. Nature 396: 580-584, 1998.

37. Reuter CW, Morgan MA, Grünwald V, Herrmann TR, Burchardt $\mathrm{M}$ and Ganser A: Targeting vascular endothelial growth factor (VEGF)-receptor-signaling in renal cell carcinoma. World J Urol 25: 59-72, 2007.

38. Rini BI and Rathmell WK: Biological aspects and binding strategies of vascular endothelial growth factor in renal cell carcinoma. Clin Cancer Res 13: 741s-746s, 2007. 